\title{
Dynamic assessment of a cable-stayed footbridge under earthquake sequence using a concrete damage plasticity model (CDP)
}

\author{
Rafat Ciura ${ }^{1}$, Izabela Drygała $^{1, *}$, Joanna M. Dulinska ${ }^{1}$ \\ ${ }^{1}$ Cracow University of Technology, Warszawska 24, 31-155 Krakow, Poland
}

\begin{abstract}
In this paper, the investigation of the dynamic response of a cable-stayed footbridge with steel reinforced concrete deck to foreshocks, a mainshock and an aftershock seismic sequence is delivered. For the aim of the study the finite element (FE) model was prepared with the ABAQUS/Standard software program. The representative seismic events with three components were taken into account in the numerical simulation. For the evaluation of seismic-induced damages in reinforced concrete deck of the footbridge, the concrete damage plasticity (CDP) model was applied.
\end{abstract}

\section{Introduction}

The dynamic studies of footbridges has been intensively deliberated upon as is marked by the large number of scientific works from both academic and commercial organisations on the topic. The numerical as well as experimental analysis were conducted for a variety of motives, including: research of the dynamic response of footbridges to usage-generated loading, aerodynamic response, correlation of numerical solutions with measured dynamic characteristics, seismic assessment, structural health monitoring of footbridges [1-3].

The studies of damages of civil engineering structures caused by seismic as well as paraseismic loading have revealed that the protection of these structures turned out to be a problematic technical task [4]. Especially for footbridges erected on seismic activity areas, the dynamic loading caused by an earthquake occurs one of the most destructive issues [3]. Therefore, structures of this type, which are infrastructure landmarks, have to be protected and, if necessary, strengthen against earthquakes. It must be also pointed out, that the vast majority of seismic mainshocks are usually preceded by foreshocks or succeeded by aftershocks within a short period of time. Hence, considering the earthquake loading and its influence on structure, it is strictly justifiable to consider full sequence of seismic events.

In this paper, the results of numerical evaluations of destructions of the reinforced concrete deck of the cable-stayed footbridge under earthquake sequence are presented. The footbridge was subjected to foreshock-mainshock-aftershock earthquakes sequence which were recorded in Central Italy, i.e. Umbria region, in 2016 [5]. The concrete damage plasticity (CDP) model was implemented as a constitutive elasto-plastic model of concrete material [6-9].

\footnotetext{
*Corresponding author: idrygala@pk.edu.pl
} 


\section{Structural layout and FE model of the footbridge}

For the purposes of the research, a three-span cable-stayed footbridge was chosen as a case study. The structure is shown in Figure 1. The footbridge is located in Southern Poland and it serves to carry pedestrians above the S7 national expressway [10]. The structure was erected in 2017 and it was designed according to Polish national standards [11].

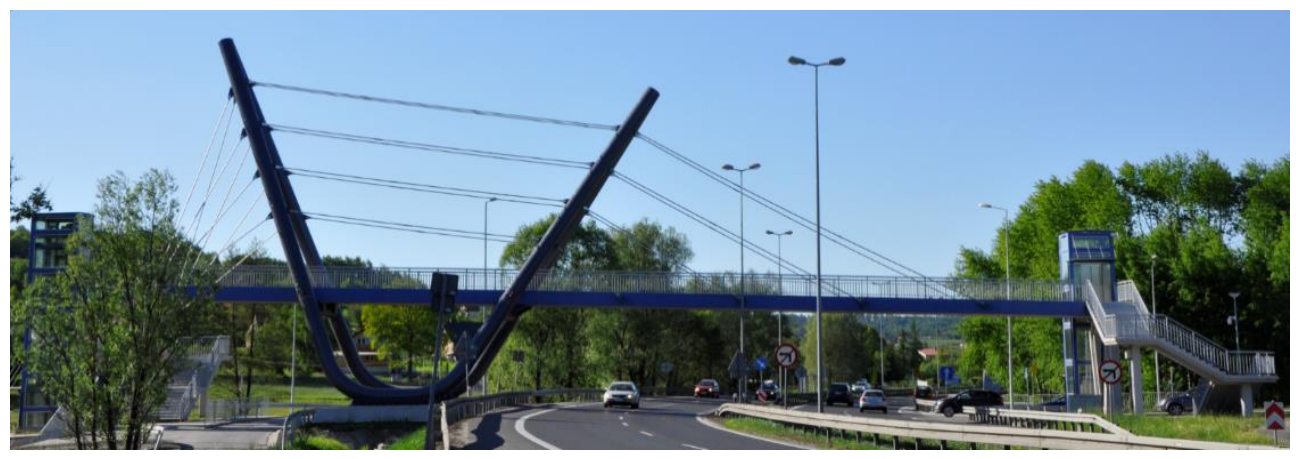

Fig. 1. Side view of the cable-stayed footbridge.

The primary structural system of the suspended structure is mainly composed of steel pylon. The footbridge deck is a steel reinforced concrete slab supported by concrete girders and steel cross bars. The deck is attached to steel pylon with steel cables as linking elements. The total length of the footbridge is $52.36 \mathrm{~m}$ and it is supported by three reinforced concrete pillars. The pillars are founded on reinforced concrete piles. The 3D finite element (FE) model of the footbridge was prepared with ABAQUS/Standard software program (see Fig. 2). For numerical analysis, the modulus of elasticity of steel parts of the structure was assumed as $210 \mathrm{GPa}$. The Poisson's ratio was assumed as 0.30 . The material data of concrete were assumed: the modulus of elasticity $-34 \mathrm{GPa}$, the Poisson's ratio -0.20 and the mass density $-2500 \mathrm{~kg} / \mathrm{m}^{3}$. The structure is equipped with elastomeric bearings which are the linking elements between the girders and the piers. In the study the parameters of the Mooney-Rivlin model (assumed as $\mathrm{C}_{10}=0.292 \mathrm{MPa}$ and $\mathrm{C}_{01}=0.177 \mathrm{MPa}$ ) were replaced with the equivalent elasticity modulus $(2.814 \mathrm{MPa})$. Such simplification is used in calculations of bridges with elastomeric bearings $[12,13]$. The Poisson's ratio of elastomeric material was taken as 0.49 .

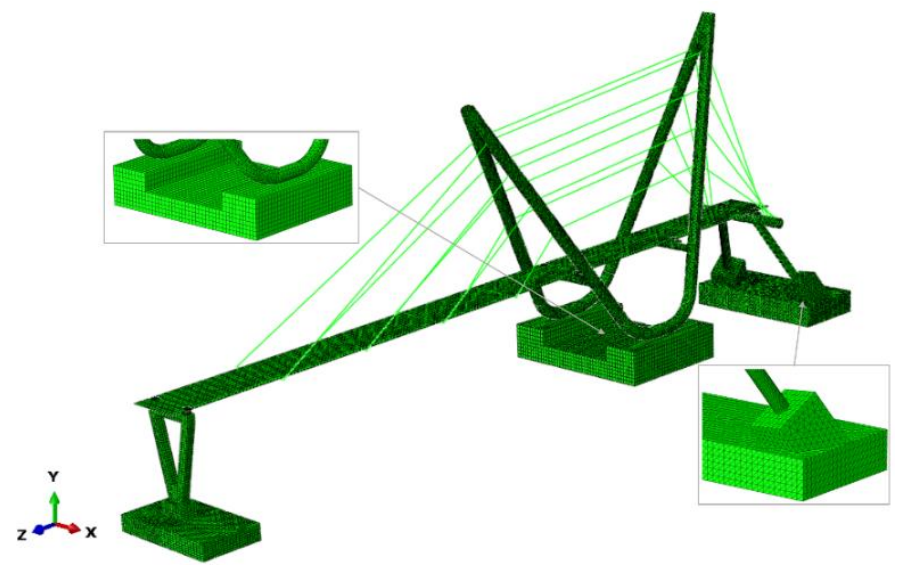

Fig. 2. FE model of the structure. 


\section{Modal parameters of the structure}

As a product of the first stage of the numerical analysis, the set of four natural frequencies and mode shapes of the footbridge is presented. The dynamic characteristics of the structure were extracted by a linear perturbation numerical procedure provided by the ABAQUS/Standard software program [9]. In Fig. 3, the mode shapes as well as natural frequencies of vibrations of the investigated footbridge are presented. The calculated first natural frequency $\left(f_{1}\right)$ was compared with a natural frequency $\left(f_{1 . C}\right)$ which was estimated from the dynamic proof loading test of the structure [10]. The value of $f_{1 . c}$ is equal to $2.70 \mathrm{~Hz}$, while the value of $f_{1}$ is equal to $2.57 \mathrm{~Hz}$. On the basis of proof loading test [10], the damping ratio of the structure was also assumed for the numerical purposes. For the first natural frequency the damping ratio is equal to $1.81 \%$.
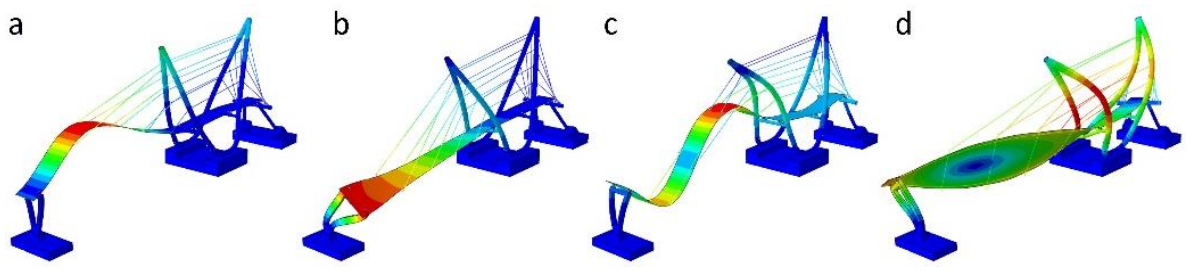

Fig. 3. The mode shapes of vibrations of the cable-stayed footbridge: a) $f_{1}=2.57[\mathrm{~Hz}]$; $\left.b\right) f_{2}=3.19[\mathrm{~Hz}]$; c) $\mathrm{f}_{3}=4.71[\mathrm{~Hz}]$; d) $\mathrm{f}_{4}=5.73[\mathrm{~Hz}]$.

\section{Earthquake sequence investigation}

The main purpose of the presented study was the dynamic assessment of the cable-stayed footbridge under earthquake sequence. Therefore, two foreshocks, a mainshock and one aftershock were discussed. The representative earthquake data registered in the region of Umbria in Preci town (central Italy, station code: T1216) were applied as kinematic excitations of the footbridge (ITACA release 2.3) [5]. The time histories of accelerations of the kinematic excitations which were used in analysis are showed in Figure 4. In Tab. 1, the peaks ground accelerations (PGAs) of the all investigated seismic events are delivered.

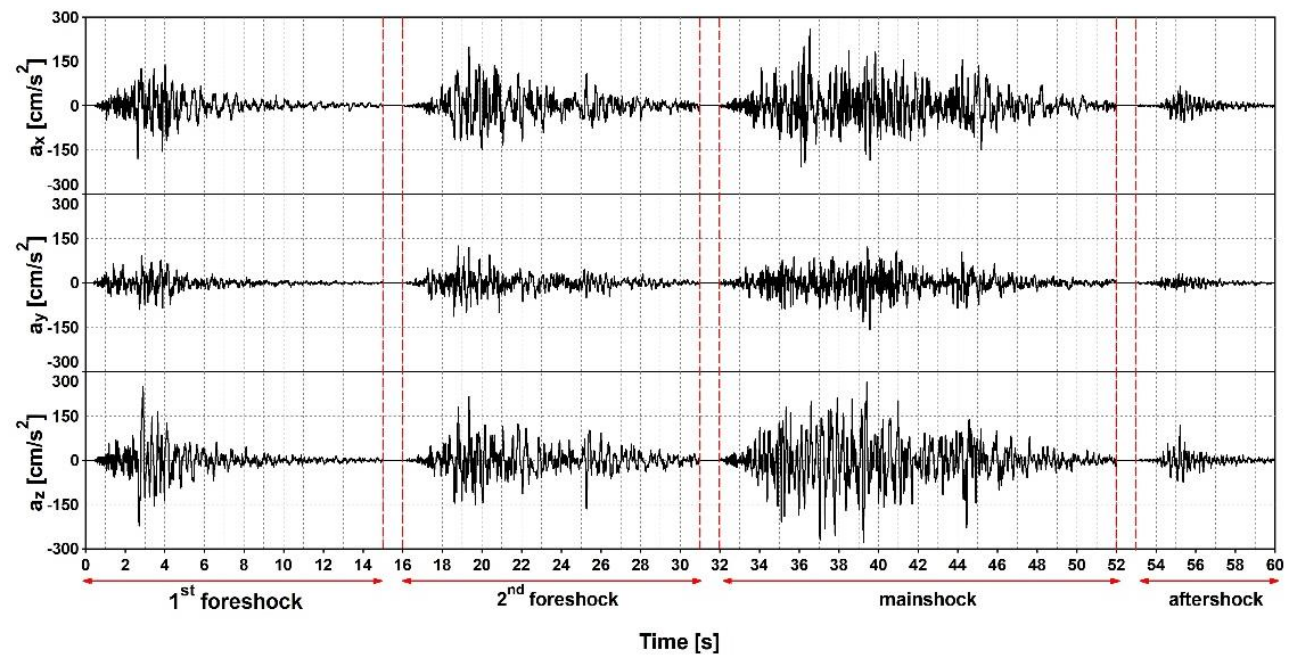

Fig. 4. Time histories of the earthquake sequence $\left[\mathrm{cm} / \mathrm{s}^{2}\right]$ in three directions: WE direction $\left(\mathrm{ax}_{\mathrm{x}}\right)$, vertical direction $\left(\mathrm{a}_{\mathrm{y}}\right)$ and NS direction $\left(\mathrm{a}_{\mathrm{z}}\right)$. 
Table 1. The peak ground accelerations (PGA) of the seismic sequence events [5].

\begin{tabular}{|c|c|c|c|c|c|}
\hline \multirow{2}{*}{$\begin{array}{c}\text { Seismic } \\
\text { event }\end{array}$} & Date & \multirow{2}{*}{$\begin{array}{c}\text { Richter } \\
\text { magnitude } \\
M_{L}\end{array}$} & \multicolumn{3}{|c|}{ The peak ground accelerations (PGA) $\left[\mathrm{cm} / \mathrm{s}^{2}\right]$} \\
\cline { 4 - 6 } & & $\begin{array}{c}\text { East-West } \\
(x \text { direction })\end{array}$ & $\begin{array}{c}\text { Up-Down } \\
(y \text { direction })\end{array}$ & $\begin{array}{c}\text { North-South } \\
(z \text { direction })\end{array}$ \\
\hline $1^{\text {st }}$ foreshock & $\begin{array}{c}2016-10-26 \\
17: 10: 36\end{array}$ & 5.4 & -180.54 & 92.10 & 249.67 \\
\hline $2^{\text {nd }}$ foreshock & $\begin{array}{c}2016-10-26 \\
19: 18: 06\end{array}$ & 5.9 & 197.91 & 126.77 & 215.75 \\
\hline mainshock & $\begin{array}{c}2016-10-30 \\
06: 40: 18\end{array}$ & 6.1 & 259.80 & -157.62 & -277.30 \\
\hline aftershock & $\begin{array}{c}2016-10-30 \\
12: 07: 00\end{array}$ & 4.6 & 67.06 & -32.95 & 118.05 \\
\hline
\end{tabular}

The recorded time histories (see Fig. 4) have been applied to all boundary conditions of the footbridge. In the numerical simulations the uniform model of ground motion was assumed. The non-linear dynamic numerical simulation of the structure to the set of seismic events was conducted with the ABAQUS/Standard software program. In the numerical analysis, the time shift between all seismic events was equal to $1 \mathrm{~s}$ and was realized as a quasistatic step implemented by implicit dynamic analysis since in this way, the complete unloading of the footbridge was provided. For the calculations the Rayleigh model of stiffness and mass proportional damping was applied. In this damping model the coefficients $\alpha$ and $\beta$ refer to mass and stiffness matrices are used. The damping coefficients $\alpha=0.6469$ and $\beta=0.0005$ were estimated for damping ratios of $1.81 \%$ [10] for the first $(2.57 \mathrm{~Hz})$ and the third $(4.71 \mathrm{~Hz})$ natural frequencies. The Hilber-Hughes-Taylor time integration procedure dedicated for a direct step-by-step solution was used. The step varied from $10^{-8}$ to $10^{-2} \mathrm{~s}$, according to convergence requirements. As it was pointed out previously, the dynamic nonlinear calculations were prepared for the reinforced concrete deck of the footbridge. For this structural part the CDP model was used [6,7]. The CDP represents the isotropic character of the concrete material and its main assumption is based on the mechanism of failure, i.e. tensile cracking and compressive crushing of the material. For the study purposes, the essential parameters of the CDP model were adopted on the basis of literature as follows: $\mathrm{E}=34 \mathrm{GPa}, \rho=2500 \mathrm{~kg} / \mathrm{m}^{3}, v=0.20$ and $\varphi=38^{\circ}$ (dilation angle) [8]. As a measurement of destruction in the deck of the footbridge the time histories of CDP variables were obtained, as follows: LEP (principal logarithmic strain variable is dedicated for strongly geometry and material non-linearity); PEEQT (tensile equivalent plastic strain); DAMAGET (tensile damage variable indicates damage occurring in the elements due to cracking); PEEQ (compressive equivalent plastic strain); DAMAGEC (compressive damage variable shows damages in areas of studied elements due to crushing); SDEG (stiffness degradation variable detects total loss of strength) [9].

\section{Results}

As a final products of the numerical simulations, the distributions of CDP variables of the studied parts related to the concrete deck of the footbridge are presented (see Figs. 5 and 6). It was observed, that the most damages occurred on the middle part of the longest span of the footbridge (see Fig. 6). In Figs. 5a-b, the distribution of the plasticization areas due to tension loading is delivered (PEEQT). In Fig. 6, the distribution of stiffness degradation variable (SDEG) after the whole seismic sequence is showed. 


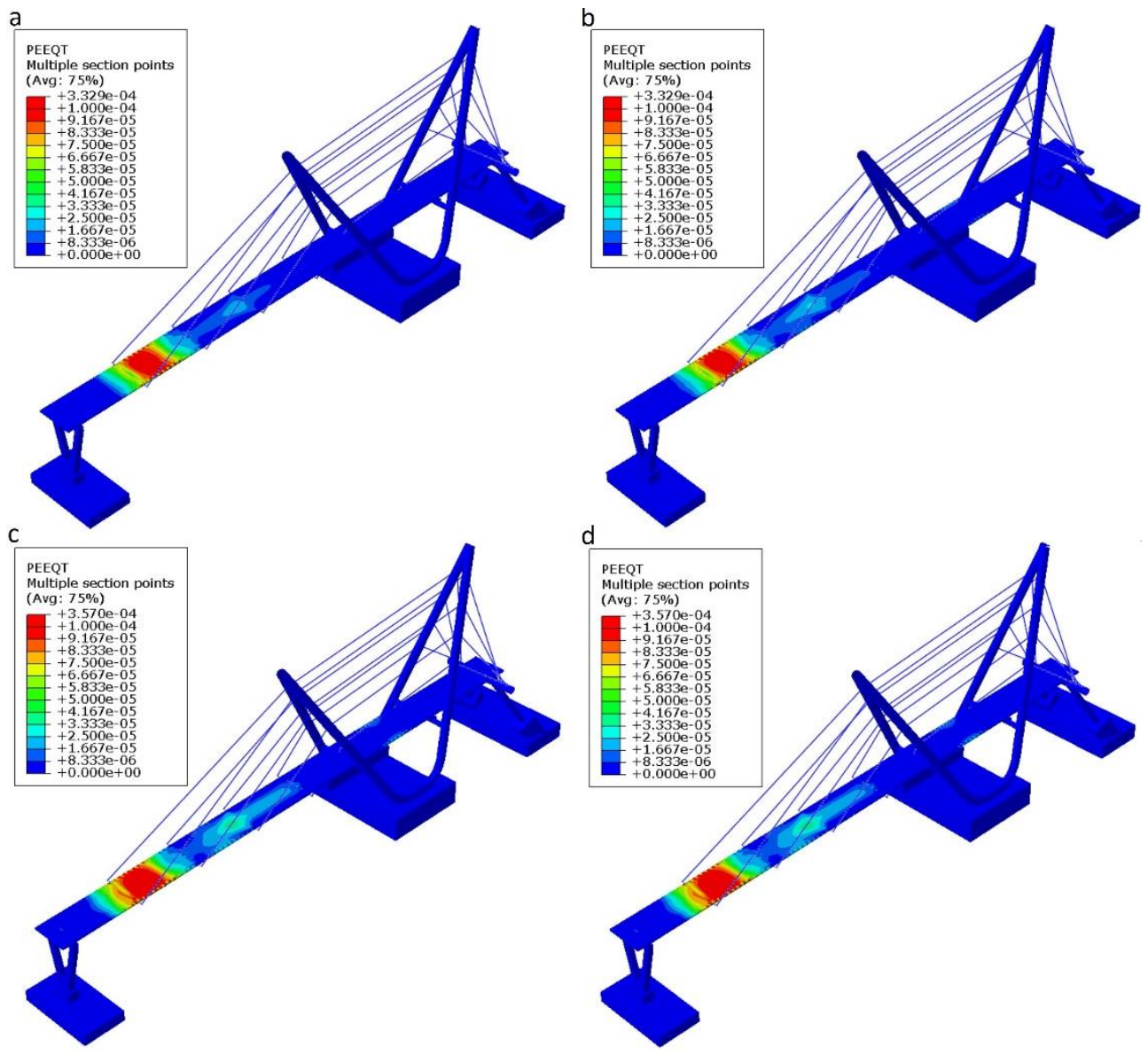

Fig. 5. Tensile equivalent plastic strain (PEEQT) due to: a) the $1^{\text {st }}$ foreshock, b) the $2^{\text {nd }}$ foreshock, c) the mainshock and d) the aftershock.

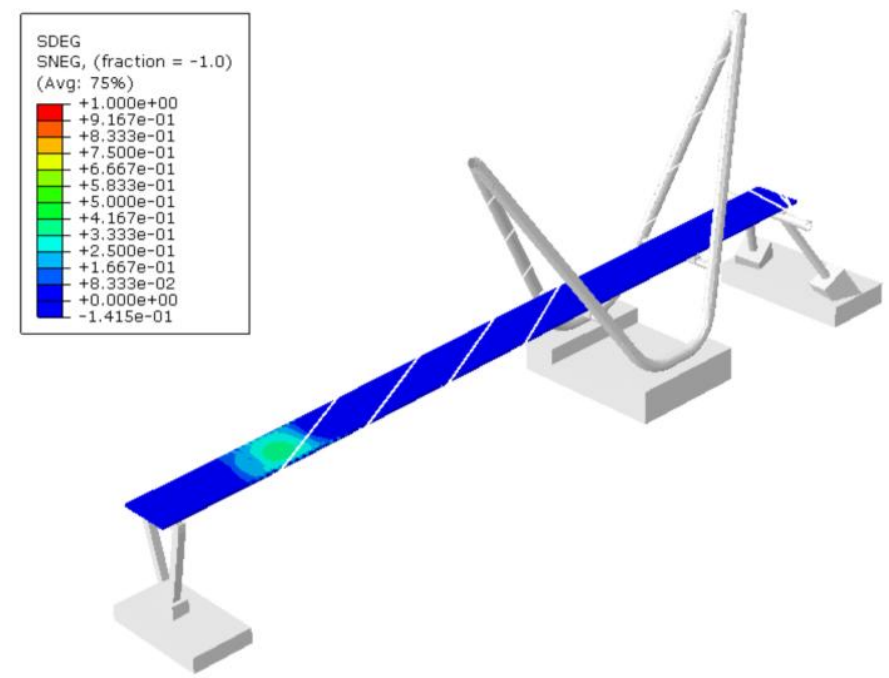

Fig. 6. Distribution of the stiffness degradation variable (SDEG) after the whole seismic sequence. 


\section{Conclusions}

The main aim of the delivered study was a numerical assessment of plastic behaviour and evolution of damages of the steel reinforced concrete deck exposed to the full foreshocksmainshock-aftershock sequence. The numerical procedures with the concrete damage plasticity model (CDP) of the plastic concrete material were conducted with ABAQUS/Standard software. Taking into consideration the obtained results of the numerical simulations following conclusions are provided:

- the numerical analysis showed that the foreshock-mainshock-aftershock sequence can cause significant damages in the steel reinforced concrete deck of the footbridge. It must be pointed out, that the first plastic zone of the investigated structural part of the footbridge was reported already after the $1^{\text {st }}$ foreshock (see Fig. 5a). On the next stages of seismic loadings, i.e. $2^{\text {nd }}$ foreshock and mainshock, the evolution of the plastic zones was noted (see Fig. 5b and c). However, it must be pointed out, that the investigated aftershock did not cause further damages of the structure (see Fig. 5c);

- discussing numerical simulation results, it is clearly visible that the calculation with the non-linear constitutive material model of concrete structures (e.g. the concrete damage plasticity model) are effective and practical tools. Taking into consideration the results, it is possible to predict the most probable location of the zones affected by destruction process during the whole seismic sequence (see Figs. 5 and 6).

\section{References}

[1] E. Lai, C. Gentile, M. G. Mulas, J. Constr. Steel Res., 132, 16-28 (2017)

[2] I. J. Murzyn, Doctoral dissertation, Cracow University of Technology (2016)

[3] I.J. Murzyn, J.M. Dulinska, M. Wazowski, Cz. T. , 4-B, 57-62 (2015)

[4] T. Tatara, F. Pachla, P. Kubon, Bulletin of Earthquake Engineering, 15, 2149-2171 (2017)

[5] ITACA - The Italian Accelerometric Archive, version 2.1 (2018)

[6] J. Lee, G.L. Fenves, J. Eng. Mech., 124, $892-900$ (1998)

[7] J. Lubliner, J. Oliver, S. Oller, E. Onate, Int. J. Solids Struct., 25, 229-326 (1989)

[8] T. Jankowiak, T. Lodygowski, Foundations of Civil and Environmental Engineering, 6, 53-69 (2005)

[9] Simulia, ABAQUS/Standard (2013)

[10]PN-S-10030:1985 (in Polish)

[11]L. Filar, J. Kaluza, M. Wazowski, Report of proof load test for the footbridge (2016)

[12] I. Buckle, S. Nagarajaiah, K. Ferrell, J. Struct. Eng., 128, 3-11 (2002)

[13] J. Dulinska, R. Szczerba, Key Eng. Mat., 531-532, 662-667 (2013) 